\title{
Plant Molecular Responses to Salt Stress ${ }^{\dagger}$
}

\author{
Loredana F. Ciarmiello *, Petronia Carillo and Pasqualina Woodrow \\ Biologiche e Farmaceutiche, Dipartimento di Scienze e Tecnologie Ambientali, Università della Campania \\ Luigi Vanvitelli, 81100 Caserta, Italy \\ * Correspondence: lorymail80@libero.it or loredanafilomena.ciarmiello@unicampania.it \\ + Presented at the 1st International Electronic Conference on Plant Science, 1-15 December 2020; Available \\ online: https://iecps2020.sciforum.net/.
}

Published: 1 December 2020

\begin{abstract}
Plants are frequenly exposed to environmental changes. In fact, abiotic stresses are the most serious factors limiting the productivity of agricultural crops, with adverse effects on germination, plant vigor and crop quality and yield. In particular, salinity stress is a global problem widespread that affects over 800 million ha. In the Mediterranean area, seawater intrusion into freshwater aquifers highly contribute to soil salinisation, resulting in crops productivity decrease. Responses to abiotic stresses are complicated pathways involving the interaction of different signalling molecules to coordinate a specific metabolic pathways. The regulation of these responses involves transcriptional factors, which regulate gene expression by binding to specific DNA promoter sequences. Transcription factors involved in salt stress responses include DRE-related binding factors, leucine zipper DNA binding proteins, putative zinc finger proteins, myb proteins, bZIP/HDZIPs, and AP2/EREBP. Particularly, AP2/ERF domain proteins include the DREB or CBF proteins binding to dehydration response elements (DRE) or C-repeats. Transcription factors are powerful targets for genetic engineering in abiotic stress resistance in crops and many studies have been focused on this topic.
\end{abstract}

Keywords: transcriptional factors; genes activation; salt stress

\section{Introduction}

Abiotic stresses are the primary cause of crop loss worldwide, reducing average yields until than $50 \%$. However, plants have evolved effective mechanisms to responde to environmental damages.

Soil salinization is a world widespread problem, particularly in arid and semiarid areas compared to the humid regions due to low rainfall (Carillo et al., 2011). It decreases the production potential of up to 46 million ha/year and is estimated that it caused an annual loss in agricultural productivity with a lost of about US\$ 31 million. Excess salt concentrations takes up to 1.5 million ha/year of farmland out of production (FAO, 2019). Soil salinization and sodification are the major processes involved in soil degradation and at global level they are declared as the most important problems for agricultural production, food security and sustainability in arid and semi-arid regions. Moreover, it led to decrease water quality, soil biodiversity and soil erosion. Particulary, in the Mediterranean basin, one of the process that contribute to soil salinity is seawater intrusion into freshwater and the irrigation with brackish water. This question is ulterior enhanced by secondary salt, which is that is accumulated in irrigated soils as water evaporates (Maggio et al., 2011).

Most crop species are glycophytes, which are salt-sensitive and are negatively affected by salinity, having to cope to ion toxicity and osmotic stress. Salt stress is due to high sodium $\left(\mathrm{Na}^{+}\right)$and chloride ( $\mathrm{Cl}-)$ ions concentrations in soil (Ismail et al., 2014). Salinity induces important changes in three stress pathways: ionic, osmotic and secondary stresses, especially oxidative stress and nutritional disorders (Yang and Guo 2018). Soil excess salts led to a reduction of water availability and plant uptake of water at the root surface, impairing cell water relations and inhibiting cell expansion and consequently growth rate (Ferchichi et al., 2018; Hasegawa et al., 2000). Ionic stress is the result of the toxic effect of salt ions inside plant cells. A long-term exposure to salinity (Table 1), expone plants to ionic stress causing plant nutritional imbalance and oxidative stress, with deep consequences for 
plant growth and development. High $\mathrm{Na}^{+}$concentration in cytoplasm and organelles negatively affect many metabolic pathways. This is probably due to high sodium concentration that can replace potassium in key enzymatic reactions (Cuin et al., 2009). Osmotic stress inhibits protein synthesis, enzyme activities and photosynthesis leading to premature leaves senescence and leaves chlorosis and necrosis (Munns and Tester, 2008). Moreover, osmotic stress can cause secondary stresses in plants, including toxic compounds accumulation and nutrient balances disruption. Reactive oxygen species (ROS) accumulate in plant cells under salt stress (Yang et al., 2018; Li et al., 2015). ROS can hardly damage cellular and subcellular membranes which leads to premature ageing and reduced crop yields (Wang et al., 2009; Genisel et al., 2015). Any way, plants under salinity stress have developed specific short-term strategies, that can take from few hours to several days, for osmotic balance, control ion and water homeostasis and to recruit stress-induced damages (Woodrow et al., 2011, 2017; Gao et al., 2016). A common salinity adapt mechanism that plants have evolved to adapt to salinity involves ions partitioning in the vacuole and synthesis and accumulation of osmolytes in the cytosol (Annunziata et al., 2017). These latter compounds protect macromolecular and alleviate oxidative stress (Shabala and Munns, 2012). Most of compatible solutes are low molecular weight nitrogen-containing metabolites such as amino acids, amines and betaines (Mansour, 2000), and sugars (Suprasanna et al., 2016; Woodrow et al., 2017). Particularly, glycine betaine plays an important role in osmoregulation, in fact, it is one of the main nitrogen-containing compatible osmolytes found in Poaceae (Annunziata et al., 2019). Plant salinity tolerance strongly depends on signalling processes as well as adaptation mechanisms and the efficiency of energy consumption of the plant species exposed to salt.

Table 1. Consequences of salt stress and plant responses.

\begin{tabular}{lll}
\hline Stress & \multicolumn{1}{c}{ Consequences } & \multicolumn{1}{c}{ Plant Responses } \\
\hline & $\begin{array}{l}\text { High } \mathrm{NaCl} \\
\text { concentrations affect } \\
\text { plant physiology and } \\
\text { metabolism at different } \\
\text { levels: water deficit, ion } \\
\text { toxicity, nutrient } \\
\text { salt } \\
\text { stress } \\
\text { stress (Vinocur \& } \\
\text { Altman, 2005; Ciarmiello } \\
\text { et al., 2011) }\end{array}$ & $\begin{array}{l}\text { Plants adopt two main responses: a rapid protective ones together } \\
\text { with a long term adaptation response. During initial exposure to high } \\
\text { salt concentrations, plants attempt water stress, which in turn reduces } \\
\text { leaf expansion. During long-term exposure to salinity, plants attempt } \\
\text { ionic stress, which can lead to premature senescence of adult leaves, } \\
\text { and thus a reduction in the photosynthetic area available to growth } \\
\text { support (Cramer \& Nowak, 1992) }\end{array}$ \\
\hline
\end{tabular}

Determining how plants adapt to salt stress could provide important advice for enhancing performance of cultivated species also via genetic engineering. In the last years, several studies were performed and advances in salt stress responses understanding were done via both genetic and biochemical analyses.

Multiple elements and transcriptional factors involved in salt adaption and signal transduction have been uncovered. We give a brief statement of the main points of plant signaling systems and regulatory mechanisms under salt stress. 


\section{Plants Adaptive Mechanisms and Signalling Pathways in Salt Stress}

Responses to salt stress are multiple pathways involving the interaction of different signalling molecules. As previeusely reported, compatible solutes play an important role in plant osmotolerance in several ways, avoiding enzymes denaturation, stabilising membranes or macromolecules and playing adaptive roles in mediating osmotic adjustment (Ashraf and Foolad, 2007). Salt Overly Sensitive (SOS) signaling pathway is made up of SOS1, SOS2 and SOS3 has been proposed to mediate cellular signaling under salinity stress. In fact, one of the earliest signalling pathways is the $\mathrm{Ca}^{2+} / \mathrm{SOS}$ cascade (Roy et al., 2014; Figure 1). $\mathrm{Ca}^{2+}$ is one of the most important signalling element in responce to plant abiotic stresses, and its cytoplasmatic concentration rapidly incease when plants are exposed to salt as a result of ri-uptake from apoplast and other intracellular compartments (Che-Othman et al., 2017; Hasegawa, 2013). The cytoplasmic $\mathrm{Ca}^{2+}$ increase activates salt overly sensitive 3 (SOS3), a $\mathrm{Ca}^{2+}$ binding protein to interact with a protein kinase salt overly sensitive 2 (SOS2; Figure 1). In fact, SOS3 encodes a calcineurin B-like protein, an EF-hand $\mathrm{Ca}^{2+}$-binding protein that act as a calcium sensor (CBL) for salt tolerance (Liu and Zhu, 1998). SOS2 encodes a Ser/Thr protein kinase known as the CBL-interacting protein kinase (CIPK) (Liu et al., 2000). The SOS2/3 kinase complex in turn activates some downstream processes, such as vacuolar sequestration of $\mathrm{Ca}^{2+}$, besides phosphorylates and activates salt overly sensitive 1 (SOS1) allowing sodium extrusion (Qiu et al., 2004). Particularly, SOS1 encodes a plasma membrane $\mathrm{Na}^{+} / \mathrm{H}^{+}$antiporter that plays a key role in sodium extrusion and in regulation of long-distance $\mathrm{Na}^{+}$transport from the root to shoot (Shi et al., 2002; Figure 1).

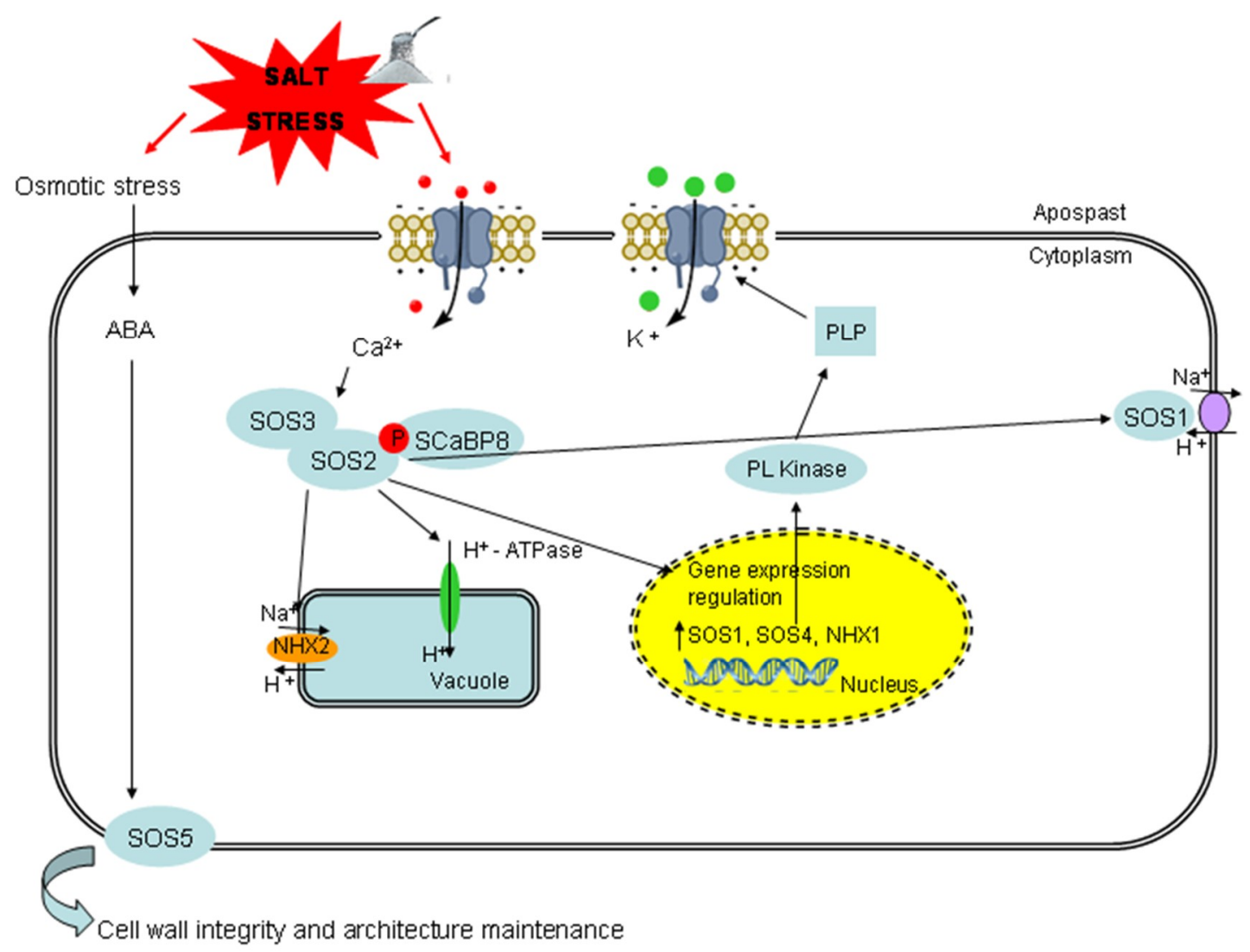

Figure 1. The Ca2+/salt overly sensitive (SOS) cascade. Under salt stress, the SOS pathway is activated by a calcium and SCaBP8 is phosphorylated by SOS2. This latter act on vacuolar H+-ATPase and $\mathrm{Na}^{+} / \mathrm{H}^{+}$exchanger. Vacuolar partitioning of $\mathrm{Na}^{+}$is mediated by the vacuolar $\mathrm{Na}^{+} / \mathrm{H}^{+}$antiporter (NHX). SOS1 sodium transport requires a proton gradient created by $\mathrm{H}^{+}$-ATPase. SOS2 enhance gene expression. SOS4 encodes a pyridoxal (PL) kinase involved in pyridoxal-5-phosphate (PLP) biosynthesis, which is associate with AKT1, a potassium channel. SOS5, a putative cell surface adhesion protein, is involved in cell expansion process. SOS = salt overly sensitive; 
$\mathrm{H}^{+}-$ATPase $=$vacuolar type ATPase; $\mathrm{NHX}=$ vacuolar $\mathrm{Na}^{+} / \mathrm{H}^{+}$antiporter. (Adapted from Yang et al., 2017).

SOS2 can also phosphorylate AtNHX1 on vacuolar membranes and activates AtNHX1 (Qiu et al. 2002, Zhu 2003). Therefore, SOS2 is a regulator for AtNHX1, linking the two salt signalling pathways. The over-expression of AtNHX1 (Zhang et al., 2001), and AVP1 (Gaxiola et al., 2001), genes that regulate ion homeostasis, was associated with salt tolerance enhancing in a SOS1 similar manner. In transgenic Arabidopsis plants were observed that the co-overexpression of AtNHX1/SOS1 confers a most salt tolerant in soil (Pehlivan et al., 2016).

In recent times, other two salt overly sensitive pathway genes were characterized, SOS4 and SOS5. SOS4 encodes a pyridoxal (PL) kinase involved in pyridoxal-5-phosphate (PLP) biosynthesis, while SOS5 has been shown to be a putative cell surface adhesion protein required in cell expansion process. Since, when salt stress occurs growth and expansion of a plant cell are negatively affected, the SOS5 role becomes priority acting in cell wall integrity and architecture maintenance (Mahajan et al., 2008; Figure 1).

Another important signalling pathway involved in the salinity response is mediated by reactive oxygen species (ROS) such as the hydroxyl radical $\left(\mathrm{OH}^{\cdot}\right)$, hydrogen peroxide $\left(\mathrm{H}_{2} \mathrm{O}_{2}\right)$, and superoxide $\left(\mathrm{O}_{2}{ }^{--}\right)$. The increased production of reactive oxygen species (ROS) is a common consequence of exposure to salt stress and other abiotic stresses. This result from excitation of the light reactions of photosynthesis inducing water splitting and electron transport. Particularly, when the latter exceeds the normal metabolism requirements, the oxygen is reduced.

Salt stress, also combined with cold stress, high light and drought result in higher ROS production because these conditions limit the availability of $\mathrm{CO}_{2}$ in photosynthesis dark reaction, leaving oxygen as one of the main reductive products (Mittler et al., 2002; Miller at al., 2006). As result, salinity induce ROS accumulation (superoxide, hydrogen peroxide and hydroxyl radicals, i.e.,) (Hasegawa, 2000). During exposure to salinity, the increased concentration of cellular ROS in turn activates the MAPK signalling cascade and down-stream responses including plant hormone synthesis, especially ABA and jasmonate and specific stress-related genes activation (Ismail et al., 2014; Figure 2). 


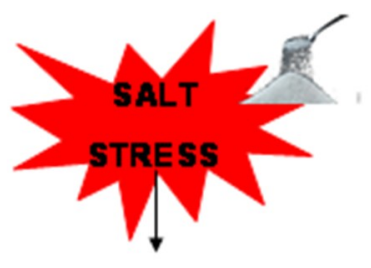

$\uparrow$ Intra- and extra-cellular ROS

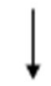

ROS sensors

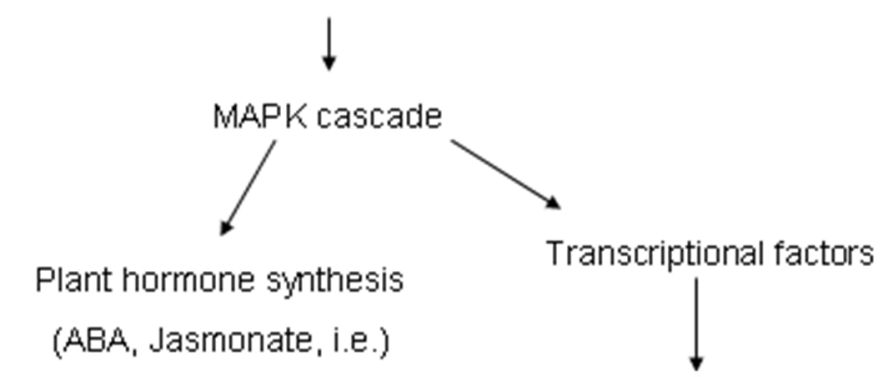

Specific related- stress genes activation

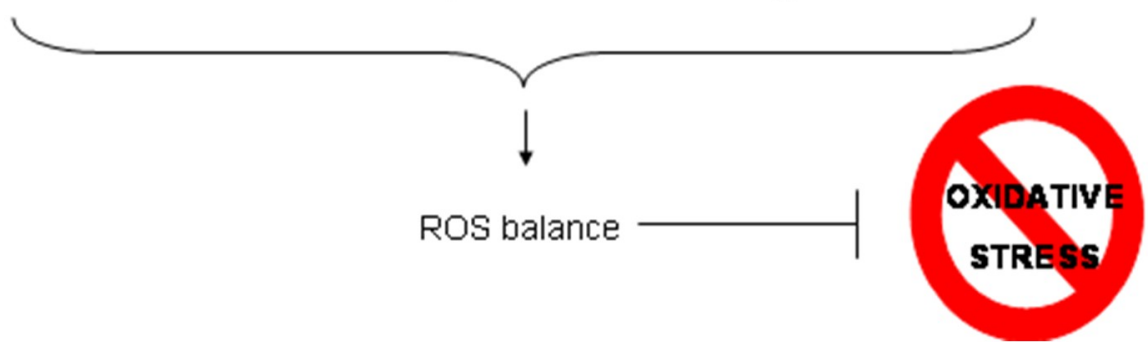

Figure 2. ROS signal transduction pathway under saltinity stress.

Some evidences have associated the up-regulation under salt stress of an EST with homology to a glycolate oxidase (T120) [GenBank n. BU671805] with ROS generation under salt stress (Fernandez et al., 2008). Several ESTs from leaf and stem cDNA libraries encoding peroxidases, thioredoxins, catalases and oxygen-evolving enhancer proteins showed transcriptional changes in response to salinity and other abiotic stresses. Generally they resulted up-regulated in stress conditions, only a $\mathrm{NADH}$-plastoquinone reductase and a catalytic hydrolase were down-regulated (Kawasaky 2001).

\section{Gene Regulation and Transcriptional Factor in Salinity Stress}

Salinity susceptibility or tolerance in plants is a coordinated action of multiple stress responsive genes. Over-expression of genes encoding Late Embryogenesis Abundant (LEA) proteins is associated with plant salt tolerance. Salt and osmotic stress regulation of LEA gene expression is mediated by both ABA dependent and independent signalling pathways and in both cases $\mathrm{Ca}^{2+}$ signalling induce LEA gene expression.

Salt stress signalling through $\mathrm{Ca}^{2+}$ and $\mathrm{ABA}$ mediates the expression of the LEA/COR salinity stress responsive genes by several up-stream transcriptional factors that activate dehydrationresponsive elements/C-repeat (DRE/CRT), ABA-responsive elements (ABREs), MYC recognition sequence (MYCRS), and MYB recognition sequence (MYBRS) cis-elements. The regulation of gene expression via DRE/CTR cis-elements is generally ABA independent. The ABA-independent pathway is widely controlled by drought response element binding protein (DREB), a family of transcription factors which contains a DNA binding motif primarily identified in a flower patterning protein called APETALA2 (AP2). It is largely observed that the expression of DREB2A and DREB2B is induced by high salt stress and dehydration in a time-depending manner (Nakashima et al., 2000). 
In Arabidopsis, AtDREB2A was induced within $10 \mathrm{~min}$ under salt stress ( $250 \mathrm{mM} \mathrm{NaCl}$ ) (Liu et al., 1998). In rice, Os-DREB2A was induced within $24 \mathrm{~h}$ after exposure to high salt concentratio $(250 \mathrm{mM}$ $\mathrm{NaCl})$.

Nowadays, not much information on the tissue-specific expression of DREBs are available. The transcription of soybean GmDREBa and GmDREBb was induced by salt, but also by cold and drought in soybean young leaves (Li et al., 2005). The DREB proteins contain an ERF/AP2 DNAbinding domain. This ERF/AP2 domain is quite conserved and the transcription factors containing it has been found in many plants, including cultivated species such as tomato (Zhou et al., 1997), tobacco (Ohme-Takagi and Shinshi, 1995), rice (Sasaki et al., 1994; Weigel, 1995) and maize (Moose and Sisco, 1996).

Conversely, ABRE and MYB/MYC element-controlled genes expression are ABA dependent pathways. ABA acrivated the basic leucine zipper transcription factors (AREB), which bind to ABRE element inducing the stress responsive gene, RD29A. The expression of RD29A depends on both DRE and $\mathrm{ABRE}$ elements and $\mathrm{ABA}$ can also induce the expression of C-repeat binding proteins, CBF1CBF3 (Chang et al., 2019).

This clearly indicate that ABA-dependent and independent transcription factors cross talk to each other in a synergistic way to enhance stress tolerance (Figure 3; Ciarmiello et al., 2014).

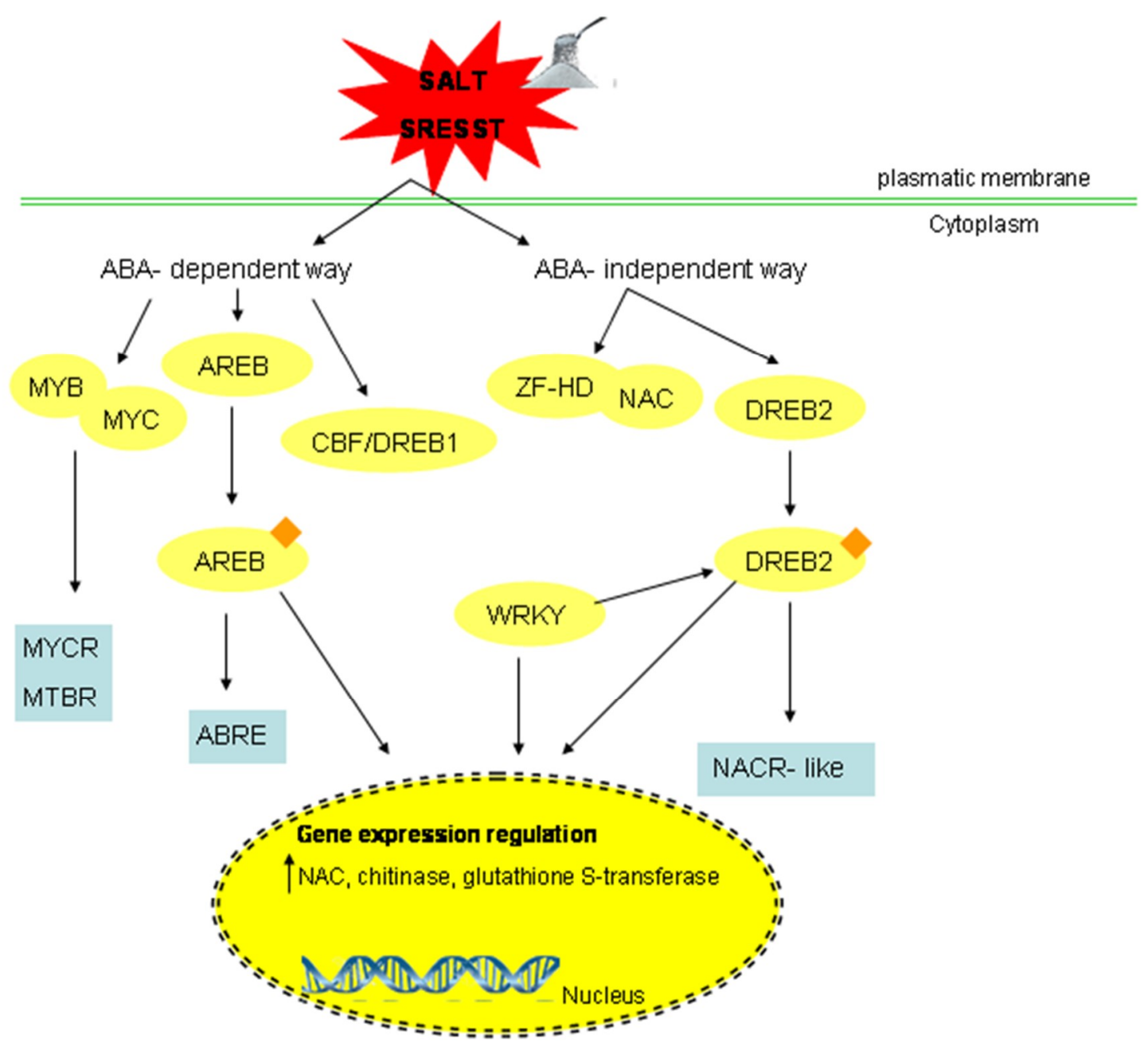

Figure 3. Transcriptional network of salt stress responses. Transcription factors are shown in ovals. The small rhombuses correspond to post-translational modifications. Sky-blue boxes represent the cis-elements present in stress-responsive genes. DREBs, WRKYs and ABREs TFs bind to stressrelated cis-regulatory elements in the promoter of regulated NAC genes and influence their transcription. (Adapted from Ciarmiello et al., 2014). 


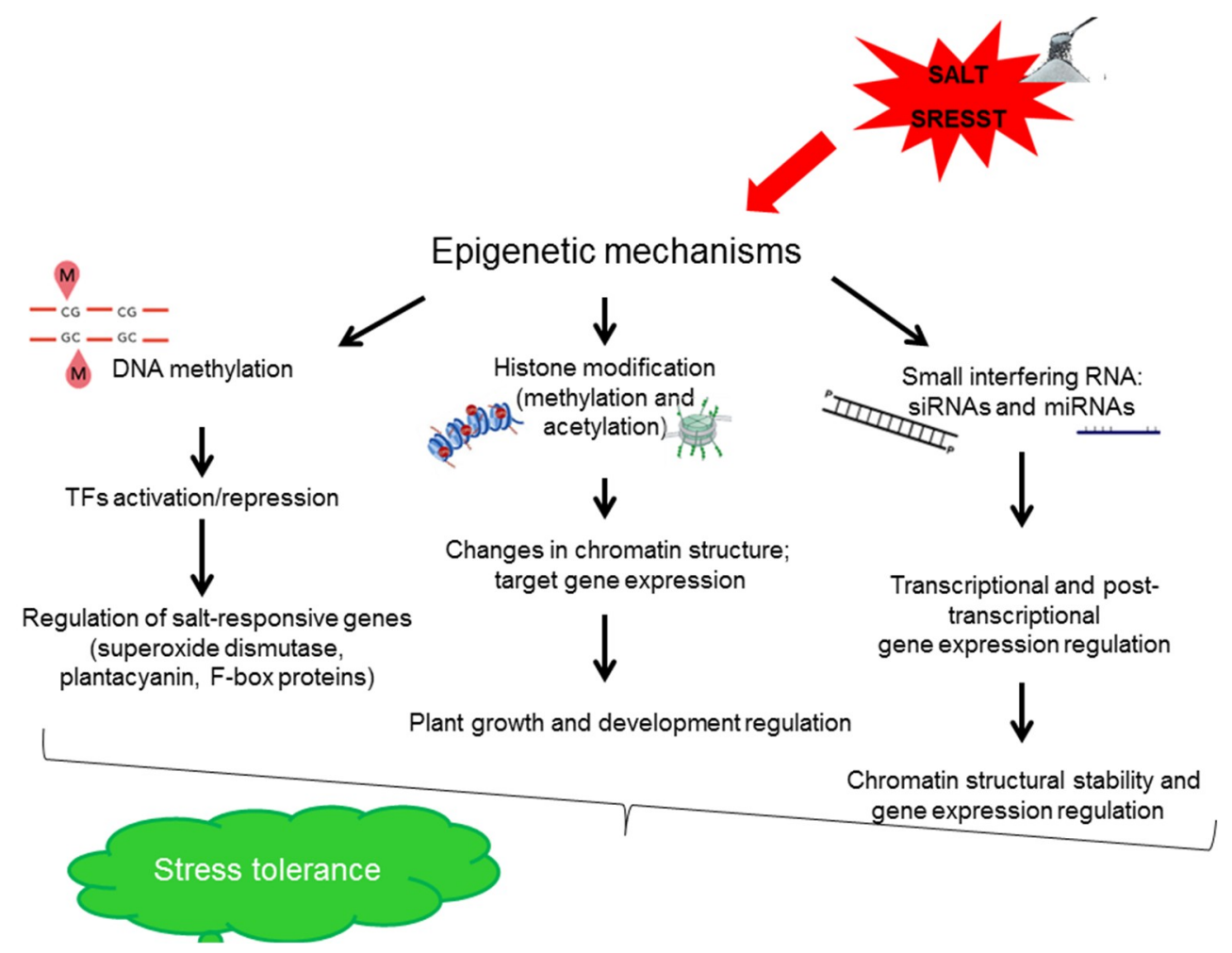

Figure 4. Epigenetic mechanisms such as DNA methylation, histone modification and small interfering RNA can regulate gene expression, playing an important role in plant stress tolerance.

An other large family of transcripional factors involved in salt stress adaption is the plantspecific NAC [no apical meristem (NAM); Arabidopsis transcription activation factor (ATAF); cupshaped cotyledon (CUC)] proteins. They constitute a major TFs superfamily known for their important functions in plant development and stress responses (Puranik et al., 2011). Some NAC TFs linked to plant response to abiotic stresses are named stress-responsive NAC (SNAC) (Nuruzzaman et al., 2010). In this latter sub-group, ANAC019, ANAC055 and ANAC072 are induced by high salinity as well as drought, cold stress (Jensen et al., 2010).

Salinity also induced the WRKY TFs. Microarray analysis in young Arabidopsis plants undergo to salt stress reveals the up-regulation of 18 WRKY and down-regulation of 8 WRKY genes (Jiang and Deyholos, 2006). WRKY TFs can regulate plant stress adaption principally in two way or via interaction with other TFs or directly by regulation of some stress-responsive genes, such as chitinase, glutathione S-transferase and strictosidine synthase (Cheong et al., 2002).

Arabidopsis plants engeneerized for GmWRKY21 and GmWRKY54 have showed an higher tolerance to high salt exposure. This is probably due to WRKY TFs ability to regulation of DREB2A (Wei et al., 2008).

\section{Epigenetic Regulation}

Gene expression can be also regulated by epigenetic mechanisms such as DNA methylation, histone modification and small RNA. These result to be particularlly imporant for plant acclimation to abiotic stresses (Kinoshita \& Seki, 2014). Recent studies based on whole-methylome sequencing in Arabidopsis have demonstrated that salt stressed plants accumulate at CG sites differentially methylated cytosines in a percentage of $45 \%$ more than controls, and of these $75 \%$ can be inherited (Jiang et al., 2014). Similarly, in rice an high percentage of DNA methylate was recorded when plants undergo to salinity (Wang et al., 2015).

Epigenetic modifications of salt-stress-inducible genes were demonstrated to be an alternative regulatory mechanism in rice plants adaption to salt stress (Karan et al., 2012).

Recently, similar results was obtained in Olea europea. It was demonstrated via Methylation sensitive amplifcation polymorphism (MSAP) an epigenetic control of specific salt-responsive genes 
in cultivated olive under severe conditions of salt stress (Mousavi et al., 2019). Under salt stress, olive plants have showed important changes in DNA methylation. Some of the methylated genes were differentially expressed in susceptible and tolerant cultivars under salinity conditions, confirming their role in plant response to salt stress.

Epigenetic modifications could play an important role in plant stress tolerance holding a memory during ri-exposure to that specific environmental stresses (Feng et al., 2015). The activation/repression of some transcription factors by DNA methylation in soybean is related to salt tolerance (Song et al., 2012).

An other important epigenetic mechanism adopt by plants in stress conditions is the histone modification. Methylation histone modification under salt stress is closely relately to regulation of plant growth and development. This is principally due to correlation between changes in chromatin structure and target gene expression. For example, the histone deacetylases HDA6 and HD2C alter the expression of stress responsive genes in Arabidopsis (Chen et al., 2010). In maize roots, salt stress induces changes in histone acetylation in the promoter region of genes involved in cell cycle (Zhou et al., 2014).

At alst, small RNAs (20-30 nucleotides) modulate target gene expression at the transcriptional and post-transcriptional levels (Zhang et al., 2006). Small RNAs can be classified based on their biogenesis and precursor structures, into small interfering RNAs (siRNAs) and microRNAs (miRNAs) (Ramachandran \& Chen, 2008). Several studies indicate that both siRNAs and miRNAs play important roles in salt-stress responses (Jian et al., 2016; Srivastava et al., 2017). In mangroves, was observed that siRNAs are involved in regulating chromatin structural stability and/or gene expression in plant undergo to high-salt conditions, enhancing stress tolerance (Wen et al., 2016). Alzahrani and coworkers (2019) recently have identified a large number of salt stress-responsive miRNAs in Vicia faba via high-throughput sequencing technology. Target prediction and annotation revealed that these miRNAs regulate specific salt-responsive genes, which mainly included genes encoding transcription factors, superoxide dismutase, plantacyanin and F-box proteins. However, further specific research programs are required and desirable to completely elucidate the epigenetic regulation of plant stress responses.

\section{Conclusions and Perspectives}

The identification of salt tolerance specific factors and signalling pathways is important for improving crop performance under high-salinity conditions.

Although, in the last decades many genetic loci linked to plant salt tolerance have been identified and cloned, the study of many factors require further elucidation. Moreover, other areas, such as $\mathrm{Na}^{+}$ signal perception, salt-triggered developmental regulation and the molecular markers for breeding salt-resistance crops, epigenetic regulation of plant salt stress responses needs to be deeper enucleated.

Nowadays significant research advances have been made on plant salt-tolerance mechanisms, however more studies are required to expand our knowledge. The elucidation of salt stress perception and the identification of key components of the salt stress responses could be an useful tool to development of efficient strategies in improvement crop salt tolerance. In particular functional analysis of transcriptional factors, genes as well as elements with key role in epigenetic control such as siRNA and miRNA, could help to explain the complex salinity stress regulatory pathways. The ability of TFs and small RNA to induce or repress the expression of stress-responsive genes may be a useful key point to develop improved crop plants resistant or tolerant to salt stress.

\section{References}

1. Alzahrani, S.M.; Alaraidh, I.A.; Khan, M.A.; Migdadi, H.M.; Alghamdi, S.S.; Alsahli, A.A. Identification and Characterization of Salt-Responsive MicroRNAs in Vicia faba by High-Throughput Sequencing. Genes 2019, 10, 303, doi:10.3390/genes10040303. 
2. Annunziata, M.G.; Ciarmiello, L.F.; Woodrow, P.; Dell'Aversana, E.; Carillo, P. Spatial and Temporal Profile of Glycine Betaine Accumulation in Plants Under Abiotic Stresses. Front. Plant Sci. 2019, 10, 230, doi:10.3389/fpls.2019.00230.

3. Annunziata, M.G.; Ciarmiello, L.F.; Woodrow, P.; Maximova, E.; Fuggi, A.; Carillo, P. Durum wheat roots adapt to salinity remodeling the cellular content of nitrogen metabolites and sucrose. Front. Plant Sci. 2017, 7, 2035, doi:10.3389/fpls.2016.02035.

4. Ashraf, M.; Foolad, M.R. Roles of glycine betaine and proline in improving plant abiotic stress resistance. Environ. Exp. Bot. 2007, 59, 206-216, doi:10.1016/j.envexpbot.2005.12.006.

5. Carillo, P.; Parisi, D.; Woodrow, P.; Pontecorvo, G.; Massaro, G.; Annunziata, M.G.; Fuggi, A.; Sulpice, R. Salt induced accumulation of glycine betaine is inhibited by high light in durum wheat. Funct. Plant Biol. 2011, 38, 139-150.

6. Chang, H.-C.; Tsai, M.-C.; Wu, S.-S.; Chang, I.-F. Regulation of ABI5 expression by ABF3 during salt stress responses in Arabidopsis thaliana. Bot. Stud. 2019, 60, 16, doi:10.1186/s40529-019-0264-z.

7. Chen, L.T.; Luo, M.; Wang, Y.Y.; Wu, K. Involvement of Arabidopsis histone deacetylaseHDA6 in ABA and salt stress response. J. Exp. Bot. 2010, 61, 3345-3353.

8. Cheong, Y.H.; Chang, H.-S.; Gupta, R.; Wang, X.; Zhu, T.; Luan, S. Transcriptional Profiling Reveals Novel Interactions between Wounding, Pathogen, Abiotic Stress, and Hormonal Responses in Arabidopsis. Plant Physiol. 2002, 129, 661-677.

9. Che-Othman, M.H.; Millar, A.H.; Taylor, N.L. Connecting salt stress signalling pathways with salinityinduced changes in mitochondrial metabolic processes in C3 plants. Plant, Cell Environ. 2017, 40, 2875-2905, doi:10.1111/pce.13034.

10. Ciarmiello, L.F.; Woodrow, P.; Piccirillo, P.; De Luca, A.; Carillo, P. Transcription Factors and Environmental Stresses in Plants. In Emerging Technologies and Management of Crop Stress Tolerance, 1st Edition, Volume 1-Biological Techniques; Ahmad, P., Rasool, S., Eds.; Elsevier: Amsterdam, The Netherlands, 2014; pp. 19-40. ISBN: 978-0-12-800876-8.

11. Cuin, T.A.; Tian, Y.; Betts, S.A.; Chalmandrier, R.; Shabala, S. Ionic relations and osmotic adjustment in durum and bread wheat under saline conditions. Funct. Plant Biol. 2009, 36, 1110-1119.

12. FAO. FAO Land and Plant Nutrition Management Service; Food and Agriculture Organization of the United Nations: Rome, Italy, 2019. Available online: https://www.eldis.org/organisation/A3599 (accessed on 30 September 2020).

13. Feng, J.; Wang, J.; Fan, P.; Jia, W.; Nie, L.; Jiang, P.; Chen, X.; Lv, S.; Wan, L.; Chang, S.; et al. Highthroughput deep sequencing reveals that microRNAs play important roles in salt tolerance of euhalophyte Salicornia europaea. BMC Plant Biol. 2015, 15, 63-79.

14. Ferchichi, S.; Hessini, K.; Dell'Aversana, E.; D’Amelia, L.; Woodrow, P.; Ciarmiello, L.F.; Fuggi, A.; Carillo, P. Hordeum vulgare and Hordeum maritimum respond to extended salinity stress displaying different temporal accumulation pattern of metabolites. Funct. Plant Biol. 2018, 45, 1096-1109, doi:10.1071/FP18046.

15. Fernandez, P.; Di Rienzo, J.; Fernandez, L.; Hopp, H.E.; Paniego, N.B.; Heinz, R. Transcriptomic identification of candidate genes involved in sunflower responses to chilling and salt stresses based on cDNA microarray analysis. BMC Plant Biol. 2008, 8, 11, doi:10.1186/1471-2229-8-11.

16. Gao, R.; Curtis, T.Y.; Powers, S.J.; Xu, H.; Huang, J.; Halford, N.G. Food safety: Structure and expression of the asparagine synthetase gene family of wheat. J. Cereal Sci. 2016, 68, 122-131, doi:10.1016/j.jcs. 2016.01.010.

17. Gaxiola, R.A.; Fink, G.R.; Hirschi, K.D. Genetic Manipulation of Vacuolar Proton Pumps and Transporters. Plant Physiol. 2002, 129, 967-973.

18. Genisel, M.; Erdal, S.; Kizilkaya, M. The mitigating effect of cysteine on growth inhibition in salt-stressed barley seeds is related to its own reducing capacity rather than its effects on antioxidant system. Plant Growth Regul. 2014, 75, 187-197.

19. Hasegawa, P.M.; Bressan, R.A.; Zhu, J.K.; Bohnert, H.J. Plant cellular and molecular responses to high salt. Annu. Rev. Plant Physiol. Plant Mol. Biol. 2000, 51, 463-499.

20. Hasegawa, P.M. Sodium (Na+) homeostasis and salt tolerance of plants. Environ. Exp. Bot. 2013, 92, $19-31$.

21. Hasegawa, P.M.; Bressan, R.A.; Zhu, J.K.; Bohnert, H.J. Plant cellular and molecular responses to high salinity. Annu. Rev. Plant Physiol. Plant Mol. Biol. 2000, 51, 463-499.

22. Ismail, A.A.; Takeda, S.; Nick, P. Life and death under salt stress: Same players, different timing? J. Exp. Bot. 2014, 65, 2963-2979. 
23. Jensen, M.K.; Kjaersgaard, T.; Nielsen, M.M.; Galberg, P.; Petersen, K.; O'Shea, C.; Skriver, K. The Arabidopsis thaliana NAC transcription factor family: Structure\&ndash;function relationships and determinants of ANAC019 stress signalling. Biochem. J. 2010, 426, 183-196.

24. Jian, H.; Wang, J.; Wang, T.; Wei, L.; Li, J.; Liu, L. Identification of Rapeseed MicroRNAs Involved in Early Stage Seed Germination under Salt and Drought Stresses. Front. Plant Sci. 2016, 7, 658.

25. Jiang, C.; Mithani, A.; Belfield, E.J.; Mott, R.; Hurst, L.D.; Harberd, N.P. Environmentally responsive genome-wide accumulation of de novo Arabidopsis thaliana mutations and epimutations. Genome Res. 2014, 24, 1821-1829.

26. Jiang, Y.; Deyholos, M.K. Comprehensive transcriptional profiling of NaCl-stressed Arabidopsis roots reveals novel classes of responsive genes. BMC Plant Biol. 2006, 6, 25.

27. Karan, R.; DeLeon, T.; Biradar, H.; Subudhi, P.K. Salt Stress Induced Variation in DNA Methylation Pattern and Its Influence on Gene Expression in Contrasting Rice Genotypes. PLoS ONE 2012, 7, e40203.

28. Kawasaki, S.; Borchert, C.; Deyholos, M.; Wang, H.; Brazille, S.; Kawai, K.; Galbraith, D.; Bohnert, H.J. Gene expression profiles during the initial phase of salt stress in rice. Plant Cell 2001, 13, 889-905.

29. Kinoshita, T.; Seki, M. Epigenetic memory for stress response and Adaptation in plants. Plant Cell Physiol. 2014, 55, 1859-1863.

30. Li, J.; Liu, J.; Wang, G.; Cha, J.-Y.; Li, G.; Chen, S.; Li, Z.; Guo, J.; Zhang, C.; Yang, Y.; et al. A Chaperone Function of NO CATALASE ACTIVITY1 Is Required to Maintain Catalase Activity and for Multiple Stress Responses in Arabidopsis. Plant Cell 2015, 27, 908-925.

31. Li, X.-P.; Tian, A.-G.; Luo, G.-Z.; Gong, Z.-Z.; Zhang, J.-S.; Chen, S.-Y. Soybean DRE-binding transcription factors that are responsive to abiotic stresses. Theor. Appl. Genet. 2005, 110, 1355-1362.

32. Liu, J. A Calcium Sensor Homolog Required for Plant Salt Tolerance. Sci. 1998, 280, 1943-1945.

33. Liu, J.; Ishitani, M.; Halfter, U.; Kim, C.-S.; Zhu, J.-K. The Arabidopsis thaliana SOS2 gene encodes a protein kinase that is required for salt tolerance. Proc. Natl. Acad. Sci. USA 2000, 79, 3730-3734.

34. Liu, Q.; Kasuga, M.; Sakuma, Y.; Abe, H.; Miura, S.; Yamaguchi-Shinozaki, K.; Shinozaki, K. Two transcription factors, DREB1 and DREB2, with an EREBP/AP2 DNA binding domain separate two cellular signal transduction pathways in drought- and low-temperature-responsive gene expression, respectively, in Arabidopsis. Plant Cell 1998, 10, 1391-1406.

35. Maggio, A.; De Pascale, S.; Fagnano, M.; Barbieri, G. Saline agriculture in Mediterranean environments. Ital. J. Agron. 2011, 6, e7, doi:10.4081/ija.2011.e7.

36. Mahajan, S.; Pandey, G.K.; Tuteja, N. Calcium- and salt-stress signaling in plants: Shedding light on SOS pathway. Arch. Biochem. Biophys. 2008, 471, 146-158.

37. Mansour, M.M. Nitrogen Containing Compounds and Adaptation of Plants to Salinity Stress. Biol. Plant. 2000, 43, 491-500, doi:10.1023/A:1002873531707.

38. Iller, G.M.; Ittler, R.O.M. Could Heat Shock Transcription Factors Function as Hydrogen Peroxide Sensors in Plants? Ann. Bot. 2006, 98, 279-288.

39. Mittler, R. Abiotic stress, the field environment and stress combination. Trends Plant Sci. 2006, 11, 15-199.

40. Moose, S.P.; Sisco, P.H. Glossy15, an APETAL2-like gene from maize that regulates leaf epidermal cell identity. Genes Dev. 1996, 10, 3018-3027.

41. Mousavi, S.; Regni, L.; Bocchini, M.; Mariotti, R.; Cultrera, N.G.M.; Mancuso, S.; Googlani, J.; Chakerolhosseini, M.R.; Guerrero, C.; Albertini, E.; et al. Physiological, epigenetic and genetic regulation in some olive cultivars under salt stress. Sci. Rep. 2019, 9, 1-17, doi:10.1038/s41598-018-37496-5.

42. Munns, R.; Tester, M. Mechanisms of Salinity Tolerance. Annu. Rev. Plant Biol. 2008, 59, 651-681.

43. Nakashima, K.; Shinwari, Z.K.; Sakuma, Y.; Seki, M.; Miura, S.; Shinozaki, K.; Yamaguchi-Shinozaki, K. Organization and expression of two Arabidopsis DREB2 genes encoding DRE-binding proteins involved in dehydration- and highsalinity-responsive gene expression. Plant Mol. Biol. 2000, 42, 657-665.

44. Nuruzzaman, M.; Manimekalai, R.; Sharoni, A.M.; Satoh, K.; Kondoh, H.; Ooka, H.; Kikuchi, S. Genomewide analysis of NAC transcription factor family in rice. Gene 2010, 465, 30-44.

45. Ohme-Takagi, M.; Shinshi, H. Ethylene-inducible DNA binding proteins that interact with an ethyleneresponsive element. Plant Cell 1995, 7, 173-182.

46. Pehlivan, N.; Sun, L.; Jarrett, P.; Yang, X.; Mishra, N.; Chen, L.; Kadioglu, A.; Shen, G.; Zhang, H. Cooverexpressing a Plasma Membrane and a Vacuolar Membrane Sodium/Proton Antiporter Significantly Improves Salt Tolerance in Transgenic Arabidopsis Plants. Plant Cell Physiol. 2016, 57, 1069-1084, doi:10.1093/pcp/pcw055. 
47. Puranik, S.; Jha, S.; Srivastava, P.S.; Sreenivasulu, N.; Prasad, M. Comparative transcriptome analysis of contrasting foxtail millet cultivars in response to short-term salinity stress. J. Plant Physiol. 2011, 168, 280287.

48. Qiu, Q.-S.; Guo, Y.; Dietrich, M.A.; Schumaker, K.S.; Zhu, J.-K. Regulation of SOS1, a plasma membrane $\mathrm{Na}+\mathrm{H}+$ exchanger in Arabidopsis thaliana, by SOS2 and SOS3. Proc. Natl. Acad. Sci. USA 2002, 99, 84368441.

49. Qiu, Q.-S.; Guo, Y.; Quintero, F.J.; Pardo, J.M.; Schumaker, K.S.; Zhu, J.-K. Regulation of Vacuolar Na+/H+ Exchange inArabidopsis thalianaby the Salt-Overly-Sensitive (SOS) Pathway. J. Biol. Chem. 2004, 279, 207215.

50. Ramachandran, V.; Chen, X. Small RNA metabolism in Arabidopsis. Trends Plant Sci. 2008, 13, 368-374.

51. Roy, S.J.; Negrão, S.; Tester, M. Salt resistant crop plants. Curr. Opin. Biotechnol. 2014, 26, 115-124.

52. Sasaki, T.; Song, J.; Koga-Ban, Y.; Matsui, E.; Fang, F.; Higo, H.; Nagasaki, H.; Hori, M.; Miya, M.; Murayama-Kayano, E.; et al. Toward cataloguing all rice genes: Large scale sequencing of randomly chosen rice cDNAs from a callus cDNA library. Plant J. 1994, 6, 615-624.

53. Shabala, S.; Munns, R. Salinity Stress: Physiological Constraints and Adaptive Mechanisms; CABI: Wallingford, UK, Sci USA 2012; Volume 94, pp. 7076-7081.

54. Shi, H.; Quintero, F.J.; Pardo, J.M.; Zhu, J.K. The putative plasmamembrane $\mathrm{Na}^{+} / \mathrm{H}^{+}$antiporter SOS1 controls long-distance $\mathrm{Na}^{+}$transport in plants. Plant Cell 2002, 14, 465-477.

55. Song, Y.; Ji, D.; Li, S.; Wang, P.; Li, Q.; Xiang, F.The dynamic changes of DNA methylation and histone modifications of salt responsive transcription factor genes in soybean. PLoS ONE 2012, 7, e41274.

56. Srivastava, A.K.; Sablok, G.; Hackenberg, M.; Deshpande, U.; Suprasanna, P. Thiourea priming enhances salt tolerance through co-ordinated regulation of microRNAs and hormones in Brassica juncea. Sci. Rep. 2017, 7, 45490 .

57. Suprasanna, P.; Nikalje, G.C.; Rai, A.N. Osmolyte accumulation and implications in plant abiotic stress tolerance. In Osmolytes and Plants Acclimation to Changing Environment: Emerging Omics Technologies; Iqbal, N., Nazar, R., Khan, N.A., Eds.; Springer: New Delhi, India, 2016; pp. 1-12.

58. Wang, W.; Huang, F.; Qin, Q.; Zhao, X.; Li, Z.; Fu, B. Comparative analysis of DNA methylation changes in two rice genotypes under salt stress and subsequent recovery. Biochem. Biophys. Res. Commun. 2015, 465, 790-796.

59. Wang, W.B.; Kim, Y.H.; Lee, H.S.; Kim, K.Y.; Deng, X.P.; Kwak, S.S. Analysis of antioxidant enzyme activity during germination of alfalfa under salt and drought stresses. Plant Physiol. Biochem. 2009, 47, 570-577.

60. Wei, W.; Zhang, Y.; Han, L.; Guan, Z.; Chai, T. A novel WRKY transcriptional factor from Thlaspi caerulescens negatively regulates the osmotic stress tolerance of transgenic tobacco. Plant Cell. Rep. 2008, 27, 795-803.

61. Weigel, D. The APETELA2 domain is related to a novel type of DNA binding domain. Plant Cell 1995, 7, 388-389.

62. Wen, M.; Lin, X.; Xie, M.; Wang, Y.; Xu, S.; Liufu, Z.; Wu, C.; Shi, S.; Tang, T. Small RNA transcriptomes of mangroves evolve adaptively in extreme environments. Sci. Rep. 2016, 6, 27551.

63. Woodrow P, Ciarmiello LF, Annunziata MG, Pacifico S, Iannuzzi F, Mirto A, D’Amelia L, Dell' Aversana E, Piccolella S, Fuggi A, Carillo P (2017) Durum wheat seedling responses to simultaneous high light and salinity involve a fine reconfiguration of amino acids and carbohydrate metabolism. Physiol. Plant. 2017, 159, 290-312, doi:10.1111/ppl.12513.

64. Woodrow, P.; Pontecorvo, G.; Ciarmiello, L.; Fuggi, A.; Carillo, P. Ttd1a promoter is involved in DNAprotein binding by salt and light stresses. Mol. Biol. Rep. 2011, 38, 3787-3794, doi:10.1007/s11033-010-04943.

65. Yang, Y.; Guo, Y. Elucidating the molecular mechanisms mediating plant salt-stress responses. New Phytol. 2018, 217, 523-539, doi:10.1111/nph.14920.

66. Zhang, H.X.; Blumwald, E. Transgenic salt-tolerant tomato plants accumulate salt in foliage but not in fruit. Nat. Biotechnol. 2001, 19, 765-768.

67. Zhang, B.; Pan, X.; Cobb, G.P.; Anderson, T.A. Plant microRNA: A small regulatory molecule with big impact. Dev. Biol. 2006, 289, 3-16.

68. Zhou, H.; Zhang, W.; Li, L. Transcriptional regulation of cell cycle genes in response to abiotic stresses correlates with dynamic changes in histone modifications in maize. PLoS ONE 2014, 9, e106070. 
69. Zhou, J.M.; Tang, X.; Martin, G.B. The Pto kinase conferring resistance to tomato bacterial speck disease interacts with proteins that bind a cis-element of pathogenesis-related genes. EMBO J. 1997, 16, 3207-3218.

70. Zhu, J.K. Regulation of ion homeostasis under salt stress. Curr. Opin. Plant Biol. 2003, 6, 441-445.

Publisher's Note: MDPI stays neutral with regard to jurisdictional claims in published maps and institutional affiliations.

(C) 2020 by the authors. Submitted for possible open access publication under the terms and conditions of the Creative Commons Attribution (CC BY) license (http://creativecommons.org/licenses/by/4.0/). 